\title{
Influencia de las masculinidades en la construcción del concepto de familia, cultura jurídica y sociedad entre 1900 -1950. Un estudio comparativo entre México y Colombia
}

\section{Influence of masculinities in the construction of the concept of family, legal culture and society between 1900 -1950. A comparative study between Mexico and Colombia}

DOI: $10.46932 / \mathrm{sfjdv} 2 \mathrm{n} 2-025$

Received in: january 1st, 2020

Accepted in: March 30th, 2020

\author{
Alba Luz Robles Mendoza \\ Docente de la Licenciatura en Psicología \\ Institución: Facultad de Estudios Superiores Iztacala UNAM \\ Av. Ejidos No. 1. Los Reyes Iztacala, Tlalnepantla Estado de México \\ E-mail: albpsic@unam.mx \\ Nancy Andrea Forero Castillo \\ Docente de la Licenciatura en Derecho \\ Institución: Facultad de Derecho. Fundación Universitaria Los Libertadores \\ Carrera 16 \#63a-68, Bogotá, Cundinamarca, Colombia \\ E-mail: forerocastillo@gmail.com
}

\section{RESUMEN}

Introducción: La masculinidad es un conjunto de características, valores y comportamientos que una sociedad impone a un varón. Los hombres construyen su masculinidad, es decir, aprenden a comportarse de acuerdo con el lugar y momento histórico en el que viven, donde el modelo tradicional masculino es el que define cómo deben sentir, pensar y comportarse. Entre algunos de los atributos que el varón debe poseer para considerarse como un hombre socialmente aceptado, están el ser poderoso, fuerte, rudo, competitivo, dominante, triunfador y seguro de sí mismo. Sin embargo, cada hombre tiene la capacidad de decidir si está de acuerdo con los patrones de conducta impuestos, o bien, prefiere vivir su masculinidad de manera diferente; de tal manera que no hay sólo una expresión, sino muchas masculinidades. Objetivo: identificar cómo las masculinidades contribuyen en la noción de cultura jurídica, familia y sociedad entre los años 1900 a 1950 haciendo un estudio comparativo entre México y Colombia. Método: Es un estudio comparativo histórico conceptual de carácter cualitativo el cual, a través de la exploración de textos de carácter jurídico, psicológico, histórico, sociológico y cultural, permita determinar cómo las masculinidades han influido en la construcción del concepto de familia y cultura jurídica y cómo estos preceptos siguen vigentes en la actualidad. Resultados: Las dominancias androcéntricas colocan al varón en posición cultural y educativa superior y en proceso de cambio hacia el establecimiento determinante de las clases sociales y de diferenciación del género. Conclusiones: El desarrollo socio-histórico que la masculinidad ha tenido demuestra la influencia de los contextos sociales en las identidades masculinas, así como en sus prácticas paternas y de representación social.

Palabras Claves: Masculinidades, Familia, Cultura jurídica. 


\section{INTRODUCCIÓN}

Hablar de la familia pareciera ser un tema fácil, por ser cercano a cada una de las personas que la conforman o que integran parte de ella, pero en realidad es una institución con un entramado difícil de develar, no solo desde las prácticas sociales sino desde la misma norma social y jurídica que la estructura. En este artículo, se hará alusión a la familia y a la construcción de las masculinidades en la primera mitad del siglo XX, tanto en Bogotá, D.C. Colombia como en la Ciudad de México. Para ello, es indispensable manifestar que, para el período de 1900 a 1950, en estos países no había un concepto de familia desde la normatividad socio-jurídica, sino que, con apoyo de otras disciplinas como la antropología, sociología y psicología, empezaron a revisar el tema de la composición familiar, desde las diferentes regiones o zonas geográficas que la componen. En este sentido, la vida en sociedad y las prácticas sociales desarrolladas al interior de cada grupo humano de los que fueron estudiados, contribuyeron a hacer una categorización de las familias, evidenciando que efectivamente era nuclear y ante todo heterosexual.

La familia como entidad socio-histórica se encuentra enlazada con los cambios sociales actuales, por lo que sus transformaciones van de la mano de la evolución social. En este sentido, la influencia de organismos tales como el Estado, la escuela, la empresa y los medios de comunicación masiva entran en competencia con la institución familiar tanto en materia educativa como en la esfera productiva.

La influencia de los medios de comunicación masiva para seguir reforzando la imagen de la familia nuclear como modelo cultural, se asume normativamente por las instituciones educativas y de salud, a la familia compuesta por padre, madre e hijos(as), como un importante factor para el crecimiento de patologías sociales en relación a las estructuras familiares actuales. Combinado por una fuerte ideología "familiarista" y conservadora de los valores y normas tradicionales, donde la consanguinidad y parentesco son criterios básicos para las obligaciones y responsabilidades de sus miembros; lo cual conlleva al desarrollo de conflictos de identidad familiar y a la presencia de crisis en las estructuras domésticas actuales categorizándolas como "disfuncionales" o "descompuestas".

Sin embargo, las instituciones creadas e introducidas a la sociedad por el ser humano, están destinadas a ajustar y adaptar la organización familiar a los cambios sociales, los cuales evolucionan de acuerdo con las transformaciones globalizadoras e influencias internacionales. La compenetración entre el mundo privado y el público demuestra cómo la familia se hace una institución más pública, siendo el Estado Nacional el manipulador de este sistema doméstico, disolviendo los particularismos locales e individualizando a los miembros de la familia para el rompimiento de los vínculos y cohesión familiar.

La unidad familiar no es un conjunto indiferenciado de individuos que comparten actividades ligadas a su mantenimiento, sino una organización social, un microcosmos de relaciones de producción, 
de reproducción y de distribución, con una estructura de poder y con fuertes componentes ideológicos y afectivos que componen esta organización (Rodríguez, 1994).

En este sentido, la utilidad de los conocimientos psicológicos inserta en el estudio de las familias debe entenderse en términos de su aplicación social, para comprender y transformar sus realidades.

La institución familiar se ha reconocido como uno de los factores básicos de socialización y formación de las masculinidades. La transmisión de normas, valores e identidades comienza en el seno familiar, combinándose con la de otras instituciones y relaciones sociales -desde la escuela hasta la calle, desde los(as) amigos(as) hasta la autoridad policial- en el proceso de formación del sujeto, de manera complementaria o contradictoria. Los procesos de socialización y de formación ético-moral dependerán de mecanismos de compensación entre estas instituciones sociales, lo cual implica tener como objetivo el fortalecimiento de la labor socializadora familiar que permita conformar sujetos con identidad y pertenencia nacional para ser vistos(as) como constructores del futuro, y no desde el contexto de la crisis como víctimas del sistema social.

\section{MARCO HISTÓRICO SOCIAL MEXICANO}

Posterior a la segunda guerra mundial, los grandes temas de América Latina habían sido el desarrollo económico, la estabilidad política, el crecimiento de la población, la urbanización, entre otros. Sin embargo, la incorporación de la institución familiar en el análisis de los procesos sociales, económicos y políticos de los países cobra fuerza a partir de las últimas dos décadas.

Los efectos de la revolución industrial no sólo marcan el deterioro de las condiciones de vida de la base trabajadora enfrentados a una nueva organización de trabajo fabril, sino al progreso tecnológico y al aislamiento de los individuos en los nuevos centros urbanos, lo que conlleva un ámbito particularmente amenazador hacia la familia. La revolución industrial realiza la separación entre casa y trabajo, entre lugar de vida y espacio de producción, conformando una diferenciación entre lo privado y lo público, que apunta a separar los ámbitos de acción de hombres y mujeres, y, por tanto, del poder y del afecto. En este sentido, la "salida" al ámbito público de las mujeres y la "entrada" de los controles sociales en el ámbito privado permite la diversidad de fenómenos familiares que combinan aspectos ligados a las demandas sociales y al mantenimiento cotidiano de las necesidades de amor, intimidad y afecto, o bien de pertenencia y seguridad personal.

La desestructuración de la economía familiar tradicional consecuencia de la industria maquinaria, afecta las relaciones sociales familiares y económicas minimizando el recurso de la fuerza muscular varonil y favoreciendo el empleo de la mano de obra femenina e infantil, lo que trae como consecuencia el incremento de asalariados de menor costo y desestabiliza la dinámica familiar al obligar a los miembros 
de la familia a trabajar para asegurar la subsistencia del hogar. La explotación capitalista metamorfosea al obrero adulto en "equipos familiares" que proporcionan una mano de obra barata y por tal un salario semanal insuficiente. Este factor económico explica la ausencia de vida familiar en la cual se inserta actualmente las familias de clases media y baja que conlleva tanto una inseguridad en las condiciones familiares como la fragilidad de la permanencia familiar, cayendo en la miseria y el aislamiento. La conciliación entre vida familiar y vida laboral obstaculiza toda expansión afectiva y espiritual (CichelliPugeault y Cichelli, 1999).

El hombre y la mujer son seres eminentemente históricos y por tal sociales. Por ello, el orden social en formación debe seguir fundamentándose sobre una estructura familiar de acuerdo con las exigencias socioeconómicas y políticas de cada país.

En México, La población total en 1930 era de 16, 552,722 habitantes de los cuales, 5, 540,631 era población urbana y 11, 012, 091 rural, siendo el 49\% del sexo masculino y 51\% del femenino (INEGI, 1998).

Las reformas impulsadas en el Cardenismo, permitió una estabilidad relativa en el campo y en consecuencia la presencia de un Estado central muy fuerte -necesario para la época-, que comenzara a decidir la distribución de competencias no solo en los órganos de gobierno sino también en la delimitación de enormes propiedades de tierra agraria y disponibilidad de recursos (INEGI, 1998).

Esto hace que la familia cobre un principal interés para su estudio dentro de la sociología, la administración y la medicina; inscritos en la estela del cientificismo y el positivismo.

La sociología del siglo XIX, consideró a la familia como un cuerpo intermedio natural que liga al individuo con la sociedad. Cuatro son los grandes fundadores del estudio de la sociología de los vínculos familiares y que tienen influencia en el desarrollo de las estructuras familiares mexicanas. El primero, marcado por el impacto de la revolución francesa, fue Alexis de Torqueville (1805-1859), quien menciona que la organización de la familia depende de la organización de la sociedad, y su forma y funcionamiento interno varían en función del estado social circundante. El segundo fue Augusto Comte (1798-1857) heraldo de la filosofía positivista, quien caracteriza a la familia como la fuente y elemento básico de la sociedad mencionando que la sociedad humana está compuesta por familias y no por individuos. La familia constituye el verdadero elemento sociológico, brindando la entrada teórica que permite estudiar la manera en que los seres humanos están vinculados. Un tercer postulado fue desarrollado por el conservador católico Frédéric Le Play (1806-1882) quien refuerza la enunciación de Comte acerca de que la sociedad no se compone de individuos aislados e independientes sino de familias, observando las relaciones que se establecen entre ambas. Introduce el estudio teórico de la función social de la familia y su lugar moral en la sociedad. Por último, la figura teórica evocada por Émile Durkheim (1958-1917) 
consagra al estudio de la familia, que en su opinión constituye "la especie social" más antigua y simple. La familia forma un tipo natural y objetivo, donde la organización familiar no puede reducirse a la puesta en práctica de ella sin caer en preconceptos y juicios. Por ello, el análisis sociológico de la familia debe basarse en la demografía, el derecho y las costumbres, a través de las fuentes etnográficas e históricas. Durkheim hace hincapié en las fuerzas de estructuración externas que pesan sobre la familia, es decir, en su definición social; afirmando que el Estado se mezcla en la vida doméstica e incluso se vuelve día a día un factor determinante para las relaciones y vínculos entre los miembros de la misma (Cichelli-Pugeault y Cichelli, 1999).

Estos cuatro teóricos sociológicos definen el carácter institucional de la familia y afirman su historicidad. La familia no es un cuerpo abstraído del resto de la sociedad, su forma y su contenido dependen del contexto social. Por ello, cumple una función reguladora primordial para el mantenimiento del vínculo social poniendo límites a las pasiones e intereses personales de la individualización.

A partir del siglo XX y XXI, los estudios en torno a la familia presentan un vuelco de 180 grados, en donde las investigaciones hacen énfasis en un estado de "crisis familiar" justificadas por la desagregación de las familias tradicionales y de la recién multiplicación de tipos familiares distinta a la nuclear (padre, madre e hijos/as). Se inicia un proceso de "problematización" del tema de la familia que moviliza a profesionales de la psicología, pedagogía, sociología, trabajado social, política, asistentes y mediadores sociales, reemplazando a la medicina, administración y observadores sociales del siglo XIX.

Algunos de los factores que intervinieron en esta desestabilización y cambio del sistema familiar son: el shock demográfico relacionado con la caída del nacimiento de hijos e hijas y que modifica la permanencia y duración de la familia clásica, la diversidad de las formas familiares hacia una redefinición no basada en el matrimonio (familias monoparentales y recompuestas) lo cual cambia la jefatura de familia del varón hacia la mujer; el creciente envejecimiento de la población que sitúa al Estado "benefactor" en un Estado "misántropo" a la redefinición de las relaciones familiares y de responsabilidad entre sus miembros, lo que provoca que la seguridad social disminuya y desaparezca; el incremento de las familias como generadoras de empleo y sobre todo de distribuidoras de servicio, entre otras.

\section{MARCO HISTÓRICO SOCIAL COLOMBIANO}

El Estado Colombiano y en este caso la ciudad de Bogotá D.C., pasaron casi todo el siglo XX con la normatividad constitucional proveniente del siglo XIX, es por ello, que para hablar de familia no se podía ver sino desde lo estipulado en el Código Civil, por medio del artículo 113, que establecía el matrimonio. A partir de esta conceptualización se dio por entendido que esa era la manera de entender la familia porque no había un concepto claro sino una noción. Unido a lo anterior, estaba lo consignado por 
la Iglesia católica, que definía el matrimonio desde su óptica y básicamente con un objetivo claro, la procreación.

El país y la ciudad en efecto estaban bajo la potestad del catolicismo y entonces todo estaba mediado por la óptica religiosa. El Concordato de 1887, que entró en vigencia por medio de la Ley 35 de 1888, hasta 1973, era un imperativo social, incluso para los más liberales en sus formas de pensar. Luego entonces:

Art. VII: El Estado reconoce plenos efectos civiles al matrimonio celebrado de conformidad con las normas del derecho canónico. Para la efectividad de este reconocimiento la competente autoridad eclesiástica transmitirá copia auténtica del Acta al correspondiente funcionario del Estado quien deberá inscribirla en el registro civil (Concordato 1973).

La inscripción en el registro civil era una marca social. El estado civil de soltero o casado era visto con miradas de escrutinio por muchos sectores sociales. Las parejas que no tenían un vínculo matrimonial eran estigmatizadas y les daban trato peyorativo. Igual sucedía con las parejas que se casaban por el matrimonio civil, era un modo menos problemático, pero igualmente, no era bien visto, porque, ante todo, las normas divinas imperaban en el imaginario colectivo de la ciudadanía.

Pero hay que manifestar que la realidad social difiere notablemente de las normas y prácticas sociales, muchas familias estaban conformadas por la unión de un hombre y una mujer, sin acudir a ritos religiosos o civiles, porque muchas de ellas, ya tenían un vínculo anterior y no era posible divorciarse. El divorcio, también era objeto de sospecha y de miradas de indignación. Por lo anterior, había un número indeterminado de familias, pero no eran vistas como tal, por no tener el requisito fundamental del matrimonio, y para poder hacer un rastreo de esta situación, se debe revisar directamente, lo conceptuado para el matrimonio civil:

Art. 113: El matrimonio es un contrato solemne por el cual un hombre y una mujer se unen con el fin de vivir juntos, de procrear y de auxiliarse mutuamente. (Código Civil colombiano, Ley 57 de 1887).

La familia era sinónimo de matrimonio, por lo tanto, no era objeto de conceptualización desde las normas jurídicas, pero lo que los legisladores no preveían era que, en las prácticas sociales, los sujetos tenían formas diversas de conformar vínculos familiares y no siempre eran conformadas por padres e hijos(as), o algunos casos abuelos(as) y tíos(as), sino que diferían notablemente y se evidenciaban diversas tipologías familiares, que en estricto sentido no tenían denominación.

En este sentido, y ante la falta de interés desde lo jurídico por regular la materia, la investigadora social, Virginia Gutiérrez de Pineda, desarrolló variadas investigaciones, en las que se impuso la tarea de develar cómo era en efecto la conformación de la familia en el territorio colombiano. En principio su objeto de estudio fueron las conformaciones familiares de la primera mitad del siglo XX. 
Las investigaciones de Virginia Gutiérrez de Pineda, no tuvieron eco suficiente en principio debido a la situación política del Estado colombiano. Fruto de lo acontecido en el año 1948, cuando asesinaron al caudillo popular Jorge Eliécer Gaitán, quien representaba un cambio en las viejas prácticas políticas y sociales del país. Como era de esperarse, el que una mujer hiciera estudios e investigaciones de campo no era tan relevante, debido a que, en primer lugar, el discurso ha sido marcado hegemónicamente por una discriminación hacia la mujer y, en segundo lugar, porque el país estaba sumido en la violencia generalizada que no ha cesado hasta el día de hoy.

Sus investigaciones han sido publicadas en diversos libros y revistas que hasta la actualidad son referente histórico, social y antropológico de la familia colombiana. De este modo, se encuentran libros como: La familia en Colombia: estudio antropológico en 1962, La familia en Colombia: trasfondo histórico en 1963, Familia y cultura en Colombia en 1975, y Estructura, función y cambio de la familia en Colombia también en 1975. Sus estudios no son desde la norma jurídica como imperativo social, sino desde los estudios sociales. Sus estudios empiezan con una observación desde varias ópticas: demografía, socio-economía, cultura, clase social, etnia y raza, y de especial atención, el rol de lo masculino y femenino dentro de la familia. Sus indagaciones hacen la revisión de documentos respecto de las prácticas familiares de varios grupos indígenas y en específico, en el modelo de familia impuesto por los españoles en el territorio colombiano, modelo que por demás continua vigente, pero que ha debido transformarse por razones de comportamientos de los grupos sociales. "Para analizar la familia colombiana en su dinámica, parto de la consideración de que es ésta una de las instituciones de su sociedad, cuyo contenido de valores y conducta se inserta en la cultura total. En consecuencia, una acción recíproca de condicionamiento se establece entre cultura y sociedad como un todo y la familia, es entonces así, causa y consecuencia de los dos precedentes" (Gutiérrez de Pineda, 1973, p.15).

Igualmente, Gutiérrez de Pineda (1973) menciona “(...) el tradicionalismo en la familia, como un sistema de vida interno, conlleva estructuras, valores y comportamientos engranados, que se proyectan y dependen de los que dominan el ambiente dado por la sociedad y la cultura totales" (...) "A través de la estructura, y poder de sus instituciones, economía, religión, educación, milicia y política, España injerta a Colombia los moldes familiares que le eran propios. La familia se caracteriza en aquel momento histórico, por constituir una institución cuya jefatura económica se focalizaba en el padre" (p. 15-16).

De este modo, la sociedad colombiana unida a la iglesia católica se encarga de reproducir los esquemas de dominación española, que se iban imponiendo imperceptiblemente de generación en generación y de esta manera, visibilizaban la familia como padre, madre, hijos, hijas y en algunos casos abuelos, abuelas, tías y tíos. Que la familia se extendiera a tercera generación no era problemático por cuanto, se seguía el esquema patriarcal heterocentrado y heterosexual que la sociedad demandaba. En el 
libro Familia y cultura en Colombia (1994), se evidencia el panorama: "La familia, a través del cura de cada comunidad, fue parte decisiva en el proceso de asimilación de los patrones normativos traídos de la Madre Patria. Cada sacerdote consiguió la adaptación, encuadró la institución familiar dentro de las normas de su moral y mantiene vigente este control activo hasta la fecha presente. La religión se convirtió y continúa siendo en este complejo el control y ordenación de los incentivos sexuales, reglamentándolos a través del matrimonio católico" (Gutiérrez, de Pineda 1994, p. 46).

Las investigaciones de la autora se basaron en la convivencia con varios grupos sociales y en la observación de los modos de vida. De este modo, la investigadora evidencia tipologías familiares no reconocidas por la ley, pero que se dan en el contexto de las poblaciones y muestra como hay unas familias que conviven, que no son tenidas en cuenta por el ordenamiento jurídico y que, con el paso de los años, han sido reconocidas por vía jurisprudencial, por reconocimiento expreso de la Corte Constitucional.

Dentro de esta lógica, se desarrolla la familia colombiana, familias constituidas por el matrimonio católico, por el civil y otras familias que, de hecho, no eran bien vistas, por cuanto no estaban comprometidas dentro de una nominación por el ordenamiento jurídico. Las personas que constituían estas familias eran llamadas mancebos, amantes, mozos, y demás denominaciones peyorativas, que hacían que no tuvieran un trato igualitario dentro de la sociedad y dentro de la norma. Así, los hijos e hijas habidos de estas uniones no eran llamados legítimos, por el hecho de que no había un contrato, -con las solemnidades del rito o de la ley- sino que eran llamados ilegítimos o extramatrimoniales.

Solo hasta el año 1990, se aprueba la Ley 54 que trata de las Uniones Maritales de Hecho. Dicha Ley lo que hace es equiparar en derechos a las parejas de hecho, conformadas por hombre y mujer, especialmente en temas patrimoniales cambiando radicalmente la noción de familia.

\section{CONCEPTOS Y TEORÍAS SOBRE FAMILIA}

El estudio de la familia como un proceso social, nos lleva a una compleja unidad de análisis significante con dimensiones problemáticas lingüísticas para definirla. Su diversidad en cuanto a las acepciones que la integran y su ambigüedad y complejidad de existencia dentro de lo social, hace que sólo se describa algunas concepciones acerca de la misma, sin profundizar en ninguna de ellas.

a) Es un acuerdo social determinado biológicamente.

b) Es la célula básica de la sociedad a la cual da cohesión y estabilidad.

c) Es una agrupación humana universal.

d) Es una estructura emergente que surge de la interacción mutua entre personalidades sociales a lo largo del tiempo. 
e) Es una unidad que se configura a partir de las relaciones entre un hombre y una mujer legalmente unidos por la institución del matrimonio.

f) Es una unidad que comparte una residencia común y su estructura está determinada por vínculos de afecto, identidad común y apoyo mutuo.

g) Grupo social caracterizado por la residencia común, la cooperación económica y la reproducción.

h) Objeto ideológico producido estereotipadamente y potenciado con la finalidad de ejercer ciertos tipos de control social.

i) Es un sistema social abierto, dinámico, dirigido a metas y autorregulado.

j) Modo de hablar sobre relaciones sociales para definir los roles que las personas desempeñan y las estructuras de poder que la definen.

k) Conjunto organizado e independiente de unidades ligadas entre sí por sus reglas y comportamiento y por funciones dinámicas, en constante interacción entre sí y en intercambio permanente con el exterior.

Las definiciones anteriores presentan múltiples connotaciones semánticas que no resolverían toda la gama de facetas familiares que nuestra sociedad mexicana refleja a través de su historia.

Por ello, la necesidad presente de promover otros tipos de concepciones diferentes a "familia" como elementos lingüísticos alternativos, como unidades domésticas, unidades familiares, ámbito privado, ámbito doméstico, vínculo social afectivo, hogares, etc.

Similarmente, la diversidad en teorías y supuestos sobre el origen y estudio de la familia es complejo, ya que las disciplinas que lo han abordado tienen perspectivas y metodologías específicas para su análisis.

Se han identificado cuatro paradigmas para el estudio de la familia:

a) Evolucionista. - Al igual que los darwinistas, establecían diversas etapas evolutivas de la familia hasta lograr su forma actual. Se encontraba la idea de que la familia correspondía a un estado arcaico, presocial de la sociedad y que por tanto estaba condenada a disolverse a medida que las sociedades se desarrollaran. Bachofen (1861) suponía que los seres humanos vivían en una etapa de promiscuidad sexual donde cada mujer pertenecía a todos los hombres y cada hombre a todas las mujeres. De ahí que el parentesco solo podía comprobarse por línea materna (matriarcado o ginecocracia). Esta sociedad primitiva fue evolucionando a medida que surge la propiedad privada y da origen a la familia como ámbito privado del hombre (premisa desarrollada por Federico Engels).

b) Positivista

a. Interaccionismo simbólico: Desarrollado en la Escuela de Chicago con una orientación al acercamiento psicosociológico del estudio de la familia. Sus precursores son: William Isaac Thomas, Florian Znaniecki, Ernest Burgess y Kart Lewin, quienes mencionaban que la familia es la principal institución de socialización. Es una unidad de personalidades en interacción, 
esto quiere decir que no depende para su supervivencia de las relaciones armoniosas entre sus miembros ni se desintegra como consecuencia de sus conflictos; sino que vive durante tanto tiempo como tiene lugar la interacción y sólo se extingue cuando ésta cesa. Es una estructura emergente que surge de la interacción mutua entre personalidades sociales a lo largo del tiempo. La construcción social de la realidad en la vida familia será uno de los ejes de análisis de la familia correlacionando la acción social con la conciencia social (valores y actitudes compartidas).

b. Sistémico: Se basa en equiparar a la familia como un sistema orgánico que trata de mantener el equilibrio ante los factores externos. Los miembros de una familia se consideran partes interdependientes de una totalidad más amplia; la conducta de cada individuo que integra la familia afectará a todos los miembros de ésta. Se caracteriza por el estudio del desarrollo familiar de la existencia de un ciclo vital correspondientes a estadios secuenciados en los que la familia se estructura para su crecimiento; tomando en cuenta las necesidades biológicas, psicológicas y sociales de sus miembros. Por tanto, la familia responde a los cambios en la estructura de una sociedad, cambiando y adaptando sus propias formas para continuar satisfaciendo las necesidades sociales de las personas que la conforman.

c) Interpretativa: La conducta familiar es significativamente interpretable y se caracteriza por sus referencias valorativas y expresión de significados. Su análisis va más allá de sus procesos biológicosevolutivos o reacciones pasivas ante las condiciones ambientales, siendo agentes activos con capacidad racional de elegir los medios para alcanzar sus objetivos comunes. La familia es un ámbito descriptivo e interpretativo de la realidad social que refleja sus crisis, cambios y transformaciones, siendo reflexiva y adaptativa ante estas condiciones sociales.

d) Post-positivista. - Paradigmas que iniciaron a partir de los años sesenta, siendo sus representativos las siguientes teorías:

a. Enfoques fenomenológicos y etnometodológicos: Sus máximos representantes en el estudio de las familias son: Garfinkel, Heritage, Cicourel y Pollner. La familia desde este enfoque se representa, se construye y se analiza desde su discurso familiar. Es una forma de asignar significados a las relaciones interpersonales, en donde los conceptos de madre, padre, hermano(a), hijo(a) y familia son recursos para organizar descriptivamente los vínculos humanos; los cuales no solo representan el discurso familiar, sino que también transmiten las ideas compartidas de la vida doméstica. En este sentido, el uso del lenguaje verbal y no verbal familiar es el aspecto principal de la organización social de la familia. Por tanto, el concepto de familia se "cosifica" siendo solamente una categoría analítica para definir vínculos sociales. 
b. Teoría crítica y pensamiento feminista: Este análisis refleja las ideas marxistas y teóricas del enfoque feminista donde se replantea el papel de la mujer dentro de la familia y se definen las relaciones de género a través de las prácticas sociales igualitarias. El feminismo como teoría social crítica trata de evaluar, describir y explicar la historia y la estructura de las relaciones de género y su construcción social dentro de la familia.

Similarmente, la propuesta de la teoría crítica de la escuela de Frankfurt gira en torno a la familia y la autoridad, los prejuicios sociales, las formas totalitarias del poder, la subordinación de los sujetos, etc. con un fondo de carácter sociopolítico y ético. Trata de situar al individuo en el medio social en el que está inserto(a) y de tomar conciencia de las determinaciones históricas e ideológicas de su comportamiento para ser un agente de cambio de su propia posición. Por tanto, el individuo puede cambiar su ambiente y contexto social analizando su realidad objetiva a través de su experiencia subjetiva (Páez, 1984).

Después de esta revisión teórica conceptual podemos concluir que dentro de las transformaciones de las sociedades contemporáneas no ha habido una convergencia en un único modelo de familia. Esto indica que la familia está ligada a los procesos de cambios de la cultura. Si actualmente hablamos de una cultura global ligada a una gran diversidad de formas culturales, entonces la familia participa en toda esta multiplicidad de facetas sociales y relativa homogeneización de comportamientos. La familia ha dejado de ser el punto de referencia estable para definir al mundo, debido a la movilidad geográfica y social de los seres humanos, participando en la fragmentación y fluidez de la sociedad contemporánea. En este sentido, la familia en la sociedad actual se define por su diversidad y por su cohesión y solidaridad para existir. Por ello, haremos un recorrido histórico sobre el concepto de familia y su vinculación con la masculinidad en el período de 1900 a 1950.

En este sentido, en Colombia se dice de nuevo que no había desde la normatividad un concepto de familia, es a partir de la última década de la segunda mitad del siglo XX, en el año 1991 donde al cambiar la Constitución Nacional, se introduce un artículo que la conceptualiza:

Art. 42: La familia es el núcleo fundamental de la sociedad. Se constituye por vínculos naturales o jurídicos, por la decisión libre de un hombre y una mujer de contraer matrimonio o por la voluntad responsable de conformarla (Constitución Política de 1991).

Este artículo en particular ha sido garante de mucha actividad jurídica en el país, y también ha sido objeto de investigación por parte de varios sectores que exigen que la conformación de la familia no sea exclusivamente tratada desde la heterosexualidad, es decir, la familia no es solamente la conformada por un hombre y por una mujer. Es importante destacar el carácter público que se le da a la familia a partir de 1991, ya que sale de la órbita del derecho privado y se le da un carácter constitucional. Asimismo, esta Constitución introduce la Corte Construccional, organismo que en adelante sería el encargado de la 
protección y vigía de los derechos de los ciudadanos colombianos. Es precisamente esta Corte la que ha sido de especial relevancia para la consecución de derechos en la institución de la familia. Es así como, por medio de los pronunciamientos del alto Tribunal, las anteriores denominaciones del matrimonio y lo que se desprendía de éste, se empiezan a re conceptualizar, por cuanto, con esta Constitución, el Estado colombiano deja de ser confesional y se vuelve laico, prerrogativa que cambia sustancialmente la vida jurídica de la nación. De este modo, la noción de familia decimonónica se cambia y se adecua a las prácticas sociales evidenciadas a lo largo de la centuria.

\section{MASCULINIDAD E HISTORIA DE MÉXICO}

Los rasgos esenciales de la masculinidad visualizados entre 1900 y 1950 estaban entrelazados con el desarrollo de la hegemonía masculina y su androcentrismo, donde la Revolución Mexicana marca un paso decisivo para la existencia de una masculinidad dominante.

La masculinidad hegemónica de define como la construcción sociocultural e histórica que engloba diversos signos y símbolos socialmente reconocidos como lo propio de ser hombre o del deber de ser masculino. Ejemplo de esto lo vemos en los lugares donde se atiende y cuida el cuerpo masculino; las peluquerías, las barberías, la sastrería serán lugares donde la pulcritud y el vestir bien estarán asociados al ser hombre, o el baño público, donde la limpieza del cuerpo y la oposición recurrente con los putos (homosexual o gay) hacen del recinto un lugar especial para la identidad masculina; asimismo, los lugares donde se despliega la masculinidad en sus diferentes facetas, son básicamente los talleres, las pulquerías, bares y cantinas, las calles, los barrios o las mismas esquinas, donde desde ahí se observa a los demás y se da el encuentro con los Otros, con los hombres que se identifica y a partir de los cuales se define y se va construyendo o reconstruyendo su propia identidad, mediante el léxico y los rasgos del discurso masculino, los hombres podrán estar mostrando su masculinidad, en una forma que demuestre la ausencia de rasgos femeninos. El hombre debía ser ante todo, fuerte, inteligente, práctico, valeroso, firme, un ser dominador y poderoso que tuviera autocontrol sobre sus sentimientos, sus gustos y modales, su forma de hablar, de caminar y de comer, de relacionarse con los demás y de obtener placer carnal; en este sentido, el uso de la razón, la moral y la cultura urbana o civilizada, serían sus mejores armas para justificar y defender su posición de superioridad y dominio sobre los seres inferiores, débiles, e incluso, afeminados (Castellanos, 1999).

Sin embargo, no era suficiente estas características para cumplir con el deber ser de hombre; era indispensable seguir los principios básicos del ideal masculino, impuestos y sancionados por la sociedad, es decir, lograr una independencia económica a través de contraer matrimonio para conformar una nueva familia, logrando con ello el anhelado reconocimiento social. El contraer matrimonio correspondía 
directamente a la adquisición de prestigio y al reforzamiento de su masculinidad, al demostrar, al menos de forma parcial, su heterosexualidad, pero también implicaba una serie de obligaciones que en general se convertían en una carga pesada: el cuidar y mantener a su esposa, el proveerse de un buen empleo, competir con sus pares y demostrar su virilidad en el ámbito público, emprender una carrera compulsiva de procreación y reproducción, y evitar ser dañado en su patrimonio y su honor, pues estos últimos elementos afirmaban la masculinidad ante los demás hombres (Moreno, 2007).

La procreación dentro del matrimonio se convertía en un atributo más de hombría, sobre todo si los hijos procreados eran varones, pues se corroboraba de este modo el potencial masculino y su virilidad adquiría mayor respetabilidad; las relaciones extramaritales y la concepción de hijos, en esta época, sólo acentuaban el potencial viril, donde el demostrar la solvencia económica y tener la capacidad suficiente para convertirse en el único proveedor del hogar se convertía en la aspiración de todo ser hombre que buscaba reconocimiento social (Miranda, 2006).

La paternidad era la máxima expresión del deber ser de la masculinidad, sea ésta dentro o fuera del matrimonio; aunque la mayoría de los hombres vivía una paternidad ausente debido a las jornadas laborales y compromisos sociales del ámbito público. Sin embargo, la preocupación por enseñar la virilidad a sus hijos varones era una de sus mayores preocupaciones para lo cual se requería del ejercicio de la autoridad y de la imposición de la disciplina como formas de enseñanza de detentar el poder y trascender en lo social.

El deber ser masculino de finales del siglo XIX necesitaba ser ejemplificado por hombres de carne y hueso que propiciaran su imitación y reproducción en la cotidianidad, y es en ese sentido, Víctor Manuel Macías (2006, citado en Moreno, 2007), documenta la existencia de un tipo de hombre superior en la historia de México, digno representante del ideal político, social, incluso estético de su época, mejor conocido en las fuentes decimonónicas como hombres de bien, caballeros $u$ hombres de mundo ...el modelo hegemónico de masculinidad y la consumada personificación de la masculinidad liberal era representada por el presidente Porfirio Díaz, ya que, al detentar legítimamente el poder simbólico y práctico, instauraba y se adscribía, de la mejor manera al deber ser masculino. Se presentaba y representaba en las biografías como el héroe ejemplar de la niñez, modelo de virtud masculina ejemplar digno de emulación que representaba un México moderno y laico, pudiéndose establecer, de este modo, una relación directa con el modelo prescriptivo del héroe como mito poético, propuesto y analizado por Moore y Gillette, pues era garante de hombría y virilidad, al ser idealizado como rey, guerrero, mago y amante, es decir, como un buen hombre de gobierno, militar, proveedor y padre de familia, de acuerdo con los preceptos decimonónicos y a la doble moral permitida, en todos los aspectos para con el sexo dominante (Moreno, 2007 p. 39). 
La heroicidad y preponderancia del presidente Porfirio Díaz $(1890$ - 1921) fue muestra de su virilidad al defender patrióticamente al país en el campo de batalla ante la embestida extranjera, convirtiéndose en un prestigioso caudillo, cuya valentía y fortaleza serían exaltados a través de sus votos de hombre rudo, fuerte y valiente, de verdadero hombre y modelo a seguir, cuya masculinidad pretendida abarcaba criterios de hidalguía y honor como pautas de comportamiento cotidiano, siendo la representación máxima del deber ser masculino decimonónico, que legitima el status de superioridad de sus congéneres y donde son identificados todos los rasgos deseados, es decir, la superioridad, el trabajo, la virilidad, la ciudadanía y el perfil del hombre público y exitoso demostrado a través de la firme, decidida y viril conducción de la política nacional, de su heterosexualidad probada, de su capacidad reproductiva, su proveeduría para los suyos y, sus práctica cotidianas de relaciones extramaritales (Moreno, 2007).

La instauración de estos preceptos, deberes morales, prácticas, roles sociales y sexuales varoniles, indicaban la existencia de un modelo hegemónico de masculinidad a seguir, que legitimaba y sancionaba el orden existente. Este modelo se ofrecía como única alternativa socialmente posible de desarrollo para los hombres y se fundamentaba en la valentía, la fortaleza y la virilidad, así como en la heterosexualidad, la insensibilidad, la procreación, la proveeduría y el cuidado de los suyos (resaltando el sentido de pertenencia de la esposa, hijos e hijas), la doble moral sexual, el adecuado comportamiento, la forma de vestir propia para los de su sexo, y la opresión, en general de las personas socialmente inferiores.

Dentro la sociedad porfiriana y al interior de las familias, existían las relaciones entre los miembros que obedecían directamente a una jerarquización con base en el sexo y edad, misma que se reproducía en el ámbito público. La autoridad paterna estaba legitimada por un orden divino y hegemónico incuestionable que norma el ser hombre, que implica, a toda costa, los principales caracteres del hombre maduro: ser jefe de familia, heterosexual y capacidad reproductiva, tener un oficio o profesión y proveer a los suyos -como objetos de pertenencia- de sus requerimientos familiares, siendo los sistemas jurídico y educativo los que fortalecieron el proyecto liberal e ideológico de la imposición masculina en la sociedad civil para los siguientes años pertenecientes al siglo XIX (Urteaga, 2004).

\section{MASCULINIDAD E HISTORIA DE COLOMBIA}

Se puede manifestar que, en las últimas décadas en el territorio colombiano, la investigadora Mara Viveros Vigoya (2002), es quien ha liderado el estudio sobre los varones desde varias ópticas, cabe señalar que lo hace después de abordar desde varias visiones las problemáticas de las mujeres. En este aspecto, continúa con el trabajo desarrollado en principio por Gutiérrez de Pineda, sobre los roles que desempeñaban los hombres y mujeres. 
Las investigaciones sobre los hombres y lo masculino en la región son muy heterogéneas. Los primeros estudios se orientaban fundamentalmente al estudio del machismo, definido como el culto a la virilidad, o hacían parte de investigaciones sobre grupos domésticos o sobre el proceso de socialización de niños y niñas en distintos contextos sociales. Algunos de los problemas más generalizados en muchos de los estudios sobre el machismo de los años cincuenta y sesenta eran su carácter descriptivo, su tendencia a enfocar el machismo en el individuo, destacando los aspectos patológicos y negativos, y su perpetuación de una imagen estereotipada del hombre latinoamericano, particularmente del campesino y obrero (Ramírez 1995). En contraste con las deficiencias de esta literatura, a partir de la década de los ochenta, se desarrolló otro tipo de estudios sobre masculinidad, que incorporó las contribuciones académicas del feminismo a la comprensión de la construcción cultural del género, los usos de la sexualidad y las relaciones ínter e intragénero (Gomáriz 1992). Hasta ese momento la identificación de los varones con lo humano y con una serie de privilegios hace invisible la problemática de los varones en cuanto tales. Los trabajos feministas latinoamericanos permitieron la acumulación de un gran número de estudios sobre las mujeres, pero ignoraron la perspectiva sobre los varones. Pese a que los estudios de género se plantearon la necesidad de enfatizar en el aspecto relacional de este concepto, la mayoría de ellos han centrado su atención en las mujeres (Viveros, 2002, p. 51).

La cita anterior denota una problemática que siempre había estado ahí pero que no habían miradas sobre ella, debido a que, la generalidad es el pensamiento machista heterocentrado y el preguntarse por la problemática de los varones no es una prioridad. Al contrario, es un síntoma de debilidad y las mujeres son las que están en esa posición. Por lo tanto, el preguntarse por estos discursos y por las necesidades de los varones es imperioso y determinante para un cambio social.

Hay que manifestar que el caso colombiano y en especial el bogotano difieren notablemente del mexicano porque el proceso de la revolución mexicana impuso órdenes diferentes en la sociedad. Las mujeres asumieron papeles preponderantes dentro de ésta, pero, asimismo, seguían siendo las débiles y seguían estando dentro de la esfera de lo privado. Lo público era para los hombres, por lo tanto, ellos eran los fuertes, los que peleaban y en ese proceso debían mostrar sus patrones de masculinidad. La revolución mostró el predominio de lo masculino sobre lo femenino. De este modo, las familias también sufrieron un cambio fundamental. En Colombia, para la primera mitad del siglo XX, las cosas eran diferentes, el país en calma y las familias dentro de la normatividad y heterosexualidad imperantes y es solo hasta la mitad del siglo, en 1948, que empezaron los cambios y roles y se inicia con el periodo de violencia conocido hasta el día de hoy. Así las cosas, se puede evidenciar que los procesos son a la inversa en estos dos casos de estudio, pero lo interesante es que lo que sí tienen de común denominador es el discurso androcéntrico, donde efectivamente los hombres son los que deben y tienen el poder. Las sociedades están construidas 
desde lo masculino y en esa lógica, las mujeres han podido existir, no sólo en México y Colombia sino en la generalidad de las comunidades latinoamericanas. 


\section{CONCLUSIONES}

Es importante manifestar el cambio trascendental que ha tenido la noción de familia en Colombia no solo desde las prácticas sociales estudiadas por disciplinas como la antropología, la sociología, la psicología sino también desde el ordenamiento jurídico. En principio, como se evidenció en este texto, en la Constitución política de 1886, no había un concepto que hablara de la familia, y se debía recurrir a la legislación civil. Este señalamiento no era considerado necesario por cuanto, se entendía que las familias estaban constituidas por el sagrado vínculo del matrimonio y además obedecían a la estructura de familia nuclear de las sociedades occidentales.

La familia y la construcción de masculinidades, son tratadas con los patrones del siglo XIX y XX. Entonces, es a partir del año 1990 donde se empiezan a evidenciar cambios sustanciales en las normas que protejan los vínculos o las uniones de personas que en estricto sentido se convertían en familias.

Así, se empieza el estudio de las nuevas tipologías familiares que antes estaban en la sociedad, pero que no eran objeto de revisión porque no se les consideraba que existían en el ordenamiento, porque para ello debían tener una nominación y los legisladores no se habían puesto a la tarea de darle vida jurídica, por lo tanto, eran inexistente en el país. Por lo anterior, en la primera mitad del siglo XX, la familia era nuclear, heterosexual y heteronormativa, mediada indiscutiblemente por un vínculo civil o religioso, que era el que les daba su carácter legal y social en el estado colombiano.

El acercamiento desde la historia, a la construcción de los modelos de masculinidad en general y a la constitución del concepto de familia en particular, nos lleva analizar el estudio de las subjetividades, de la construcción de las identidades y de las relaciones de poder en un entramado social de interacciones sexo-genéricas; su utilidad práctica y evidente es la de complementar los estudios de las mujeres, en el sentido de lograr una percepción más amplia de la realidad humana y de los condicionantes socioculturales en los que se desenvuelven los actores sociales masculinos y femeninos que constituyen y construyen nuestra sociedad contemporánea.

\section{AGRADECIMIENTOS}

Esta investigación forma parte del Proyecto de Investigación titulado: "Masculinidades, hegemonía, patriarcado y violencias de género en Bogotá D.C. y Ciudad de México entre los años 2014-2019: estudio comparado". Agradecemos a la Fundación Universitaria Los Libertadores por el apoyo financiero a la misma (Proyecto DER-003-19). 


\section{BIBLIOGRAFÍA}

Bachofen, J.J. (1861). El matriarcado. Una investigación sobre la ginecocracia en el mundo antiguo según su naturaleza religiosa y jurídica. Madrid: Ediciones Akal.

Becerra, G. (1982). Familia y sexualidad en la Nueva España. México. Editorial Fondo de Cultura Económica.

Castellanos, G. (1999). "Malas" palabras y "buenas" palabras: exclusión, solidaridad y poder en los discursos femeninos y masculinos. En: Campuzano, L. (coord.). Mujeres latinoamericanas del siglo XX. Historia y cultura. México: UAM-I. Casa de las Américas, Tomo II, p. 234.

Cicchelli-Pugeault, C. y Cicchelli, V. (1999). Las teorías sociológicas de la familia. Buenos Aires: Ediciones Nueva Visión.

INEGI (1998) Anuario Estadístico de los Estados Unidos Mexicanos. México: Instituto Nacional de Estadística, Geografía e Informática.

Gomáriz, E. (1992). Los estudios de género y sus fuentes epistemológicas: periodización y perspectivas. Fin de siglo, género y cambio civilizatorio. Santiago de Chile: Isis internacional. Ediciones de las mujeres.

Gutiérrez de Pineda, V. (1973). Tradicionalismo y Familia en Colombia: trasfondo familiar del menor con problema civil. Bogotá: Asociación Colombiana de Facultades de Medicina. División de Medicina Social y Población.

Gutiérrez de Pineda, V. (1994) Familia y cultura en Colombia. Tipología, funciones y dinámicas de la familia. Manifestaciones múltiples a través de mosaico cultural y estructuras sociales. Bogotá: Universidad de Antioquía.

Miranda, R. (2006). La vida de un obrero y la construcción de la masculinidad (1890-1940). en Fernández M., Ramos, C. y Porter, S. (Coord.). Orden social e identidad de género. México, siglos XIX y XX. México: CIESAS. Universidad de Guadalajara, p. 306.

Moreno, S. (2007). Masculinidades en la Ciudad de México, durante el porfiriato. Una aproximación bibliográfica. Tesis de la Licenciatura en Historia. México. Universidad Autónoma Metropolitana. Unidad Iztapalapa.

Páez, G. (1984). Sociología de la familia: Elementos de análisis en Colombia y América Latina. Bogotá: Universidad Santo Tomás. Centro de enseñanza desescolarizada.

Ramírez, R. (1995) Ideologías masculinas: sexualidade e poder. En: S. Nolasco (Coord.). A desconstrucao do masculino. Rio de Janeiro: Editorial Rocco, pp. 75-83

Rodríguez, R. (1994). Familias (Siglo XXI). Santiago de Chile: Isis internacional. Ediciones de las mujeres.

Urteaga, M. (2004). Imágenes juveniles del México moderno. En: Pérez, J. A y Urteaga, M. (Coord.). Historias de los jóvenes en México: su presencia en el siglo XX. México. Secretaría de Educación Pública/Centro de Investigación y Estudios sobre Juventud-Instituto Mexicano de la Juventud/Archivo General de la Nación. pp. 33-89. 
Viveros, M. (2002). De quebradores y cumplidores. Sobre hombres, masculinidades y relaciones de género en Colombia. Bogotá. Universidad Nacional de Colombia.

Fuentes legislativas

Código Civil Colombiano (2012) Bogotá: Temis

Constitución Política de Colombia (2012) Bogotá: Legis 